\section{REVISTA ESPAÑOLA DE \\ ARTROSCOPIA \\ Y CIRUGÍA ARTICULAR}

Revista Oficial de la Asociación Española de Artroscopia (AEA)

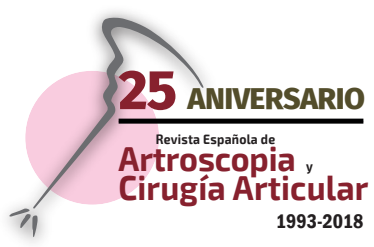

Vol. 25. Especial. Núm. 62. Mayo 2018

ISSN: 2386-3129 (impreso)

2443-9754 (online)

\title{
Editorial
}

\section{5 aniversario de la revista de la AEA}

\section{$25^{\text {th }}$ anniversary of the AEA's journal}

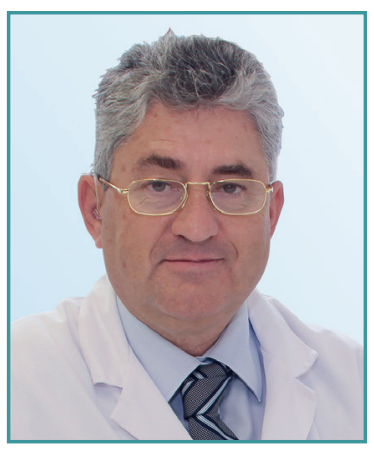

Dr. Ricardo Cuéllar Presidente de la AEA
Apreciados compañeros, queridos amigos:

oincidiendo con la edición de este número extraordinario, se produce el relevo en la presidencia de nuestra Junta Directiva. Al ceder el testigo al Dr. Eduardo Sánchez Alepuz, me siento enormemente recompensado. Ello es especialmente posible por haber gozado de vuestra confianza y apoyo a lo largo de estos años. Pero también ha sido para mí un motivo de satisfacción el haber podido celebrar, durante este periodo, el 35 aniversario de la fundación de nuestra sociedad y este 25 cumpleaños de nuestra revista.

Con este relevo en la presidencia, se produce también el de la dirección de la revista, según establece nuestra anterior revisión de estatutos. El Dr. Manuel Leyes que, por motivos laborales, hubo de delegar gran parte de su función en el Comité Editorial en los últimos meses, termina su cometido al frente de la misma. A la vez, os notifico que he aceptado con entusiasmo la propuesta de Eduardo (Sánchez Alepuz) para desempeñar la función de director de la REACA durante los dos años de vigencia de su presidencia. La REACA es una revista de comunicación y formación para los socios de la AEA que, al no estar indexada, no puede, indudablemente, competir con otras revistas internacionales que sí lo están. Pero, fieles a los principios que impulsaron su fundación ("Comunicar nuestras ideas, trucos y sobre todo los resultados de nuestras investigaciones, para que mediante su difusión y conocimiento podamos avanzar en definitiva en beneficio de nuestros pacientes"), el objetivo del Equipo Editorial será seguir manteniendo este excelente vehículo de formación y comunica- 
ción entre los socios. Perseverar en esta labor nos debe permitir que poco a poco se pueda llegar a convertir en un referente de la especialidad en lengua española sin descartar metas más altas. Pero ello será labor de todos.

Centrándonos ahora en este número extraordinario que conmemora la creación de la revista con su titulación original de Cuadernos de Artroscopia, su fundador, el Dr. Enrique Galindo, rememora aquel acontecer en una primera carta editorial; nos habla de aquel primer proyecto y las expectativas que creó la aparición de la revista en aquella novel AEA de 1993.

No es desde luego la única carta editorial de este número. En él se da cabida a un importante documento de consenso sobre el tratamiento de la rotura horizontal del cuerno posterior del menisco interno ${ }^{(1)}$. Con el lema “iSalvad el menisco!", del que probablemente muchos ya tenéis conocimiento, la revista Knee Surgery, Sports Traumatology, Arthroscopy (KSSTA) nos ha cedido los derechos de publicación pidiéndonos que lo hagamos extensivo en nuestro idioma. Su segundo editor jefe, el Dr. Roland Becker, preludia, junto a nuestro compañero el Dr. José Antonio Guerrero, este interesante trabajo de consenso europeo. Completa la aportación sobre la patología meniscal una magnífica revisión de las lesiones de la raíz meniscal, producto de la experiencia del Dr. Alejandro Espejo y su equipo.

"Trasplante osteocondral autólogo en rodilla: ¿dónde están los límites?" es otro de los interesantes artículos de revisión que integran este número. Basado en su amplia experiencia en el tema, el Dr. David Figueroa, próximo presidente de la Sociedad Latinoamericana de Artroscopia, Rodilla y Deporte (SLARD), nos lo hace llegar desde Chile.

También contamos con otra importante colaboración de nuestros amigos latinoamericanos. El Dr. Daniel Slullitel nos aporta sus extensos conocimientos en el tratamiento de la inestabilidad de hombro y la reincorporación deportiva en el jugador de rugby intervenido por dicha patología.

No solamente nuestra revista cumple años. La técnica de refuerzo capsular para el tratamiento de la luxación recidivante de hombro, diseñada por el Dr. Mikel Sánchez, también lo hace. Propiciada en momentos en los que nuestros medios eran aún precarios, alcanzó popularidad hasta el desarrollo de los actuales anclajes, que la han ido relegando en número de indicaciones. El Dr. Javier Gómez-Cimiano nos relata de forma resumida lo que han sido estos 25 años de empleo de la técnica y nos la presenta actualizada en forma de vídeo.

Complementa este número el documento de conclusiones de la primera Jornada de Actualización en Artroscopia que se celebró en las instalaciones de la Cátedra UFV-FEA (Universidad Francisco de Vitoria-Fundación Española de Artroscopia), en Madrid, del 23 al 24 de marzo. En un formato de webinar, que permitió el acceso de preguntas de los participantes a los ponentes, se debatió sobre las controversias en el "Abordaje en las lesiones del complejo posterolateral de la rodilla". En torno a diez aspectos de controversia, se refleja el mayor acuerdo alcanzado entre los participantes en la posterior discusión dirigida por el Dr. Antonio Cruz y el Dr. José Antonio Guerrero.

Cierra este número la sección, ya habitual, de imagen de portada. Sección que, como sabéis, es la base para la elección del premio Pau Golanó que se falla por primera vez este año.

Nuestra revista comienza su andadura, impulsada como se ha dicho por el Dr. Enrique Galindo, con el número 0 que apareció en octubre de 1993. Su introducción, un breve resumen de la Historia de la Artroscopia(2), firmado por la Dra. Monserrat García-Cugat y el Dr. Ramón Cugat, daba paso a dos artículos sobre una técnica también en boga por aquel entonces: la liberación endoscópica del túnel carpiano ${ }^{(3,4)}$. Como os hemos anunciado, estos artículos (y todos los que les han seguido) ya pueden ser consultados y descargados, novedosamente, en forma de archivo PDF independiente. ¡Haced la prueba!, clicad en:

\section{Técnica de liberación del túnel carpiano mediante artroscopia por una sola puerta de entrada}

https://fondoscience.com/reaca/vol0-fasc1-numo/fs9310004.tecnica-de-liberacion o 
Técnica quirúrgica para la sección endoscópica del ligamento transverso del carpo con la técnica Agee https://fondoscience.com/reaca/vol0-fasc1-numo/fs9310005.tecnica-quirurgica

Este primer fascículo contiene también la primera gran aportación anatómica de Pau Golanó, precedido por su entonces catedrático, el Dr. Domingo Ruano(5). Merece también sin duda un clic:

Artroscopia de tobillo: puertas de entrada y sus relaciones anatómicas. Anatomía artroscópica

https://fondoscience.com/reaca/vol0-fasc1-num0/fs9310007.artroscopia-de-tobillo

Esta novedad constituye sin duda un buen regalo de cumpleaños

Ricardo Cuéllar

Presidente de la AEA

\section{Bibliografía}

1. Beaufils Ph, Becker R, Kopf S, Englund M, Verdonk R, Ollivier M, Seil R. Surgical management of degenerative meniscus lesions: the 2016 ESSKA meniscus consensus. Knee Surg Sports Traumatol Arthrosc. 2017;25:335-46.

2. García, M, Cugat R. Historia de la Artroscopia. Cuad Artroscop. 1993;0(1):9-13.

3. Menon J. Técnica de liberación del túnel carpiano mediante artroscopia por una sola puerta de entrada. Cuad Artroscop. 1993;0(1):15-21.

4. Vaquero J. Técnica quirúrgica para la sección endoscópica del ligamento transverso del carpo con técnica Agee. Cuad Artroscop. 1993:0(1):22-5.

5. Ruano D, Golano P, Llusa M, Cugat R, Puig R, García M. Artroscopia de tobillo: puertas de entrada y sus relaciones anatómicas. Anatomía artroscópica. Cuad Artroscop. 1993:0(1):30-3.

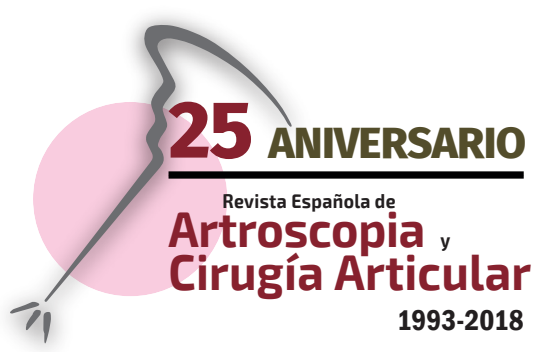

